\title{
Indeterministic Intuitions and the Spinozan Strategy
}

\author{
Andrew Kissel \\ Old Dominion University \\ Department of Philosophy and Religious Studies \\ 9011 Batten Arts \& Letters \\ Norfolk, VA 23529 \\ akissel@,odu.edu
}

\section{NOTE: THIS IS THE AUTHOR'S POST-PRINT MANUSCRIPT!!! PLEASE DO NOT CITE THIS VERSION WITHOUT PERMISSION OF THE AUTHOR.}

To appear in: Mind \& Language, 2018, Volume 33, Issue 3, pages 280-298.

https://onlinelibrary.wiley.com/doi/abs/10.1111/mila.12176

\begin{abstract}
:
This article focuses on philosophical views that attempt to explain widespread belief in indeterministic choice by following a strategy that harkens back at least to Spinoza. According to this Spinozan strategy, people draw an inference from the absence of experiences of determined choice, to the belief in indeterministic choice. Accounts of this kind are historically liable to overgeneralization. The pair of accounts defended in Shaun Nichols' recent book, Bound: Essays on Free Will and Responsibility, are the most complete and empirically plausible representatives of this strategy. I argue that both accounts ultimately fail, and overgeneralization worries remain for Spinozan strategists.
\end{abstract}

In recent years there has been increasing evidence that people tend to conceptualize their own freedom in libertarian terms (Sarkissian, 2010; Nichols and Knobe, 2007; Deery et. al., 2013; Rakos, 2008). This has led to an interest among philosophers in explaining why libertarian beliefs seems to be the default amongst the folk. The libertarian position on free will can be minimally characterized as the view that free will is incompatible with determinism, that determinism is false, and that humans have free will. If one is to be a libertarian, then, one must reject the doctrine of determinism. ${ }^{1}$ In particular, one must hold that free choices are not causally determined by prior states of affairs.

Acknowledgements: An early draft of this work was presented at the American Philosophical Association Central meeting. I would like to thank Richard Samuels, Declan Smithies, Abe Roth, Shaun Nichols, Julia Jorati, Teresa 
Since libertarian free will requires that choice not be causally determined, philosophers have sought to explain the component belief that choice is not causally determined as a partial step towards explaining the belief in libertarian free will. Many have held that the belief in indeterministic choice is, in turn, somehow based in our own experience of choosing (Campbell, 1967; O’Connor, 1995; Searle, 2003; Nichols, 2004; Pink, 2004; Swinburne, 2014). This has led philosophers - libertarian and non-libertarian alike - to seek a more complete explanation of the inference from the experience of choosing to the widespread belief in indeterministic choice.

This article focuses on a subset of views that attempt to explain the belief in indeterministic choice by following a strategy that harkens back at least to Spinoza. According to this Spinozan strategy, people do not believe their choices are indeterministic because they experience their choices as indeterministic. Rather, people come to believe their choices are indeterministic because they lack an experience of their choices being causally determined; they draw an inference from the absence of experiences of determined choice, to the belief in indeterministic choice. The Spinozan strategy can be contrasted with the straight strategy, which holds that there is a widespread experience of choice as indeterministic and that the belief in indeterministic choice is based on this experience.

Although the Spinozan strategy is attractive to many philosophers, its successful execution is far harder than one might initially suppose, as most extant presentations of the strategy are liable to overgeneralize. In this article, I focus on the pair of accounts defended in Shaun Nichols' recent book, Bound: Essays on Free Will and Responsibility. These accounts are

Kouri Kissel, Giorgio Sbardolini, Paul Robinson, Leigh Vicens, Terry Horgan, and two anonymous referees for helpful comments and discussion on earlier versions of this article.

Address for correspondence: Department of Philosophy and Religious Studies, 9011 Batten Arts and Letters Building, Norfolk, Virginia, 23529

Email: akissel@odu.edu

${ }^{1}$ I have in mind here causal determinism. See Butterfield, 1998, for more on determinism. 
the most complete and empirically plausible representatives of the Spinozan strategy.

Nevertheless, I argue that both accounts ultimately fail. Thus, overgeneralization worries remain a lingering problem for Spinozan strategists.

This article proceeds as follows: In section 1, I briefly present the Spinozan Strategy and discuss some widely accepted adequacy conditions one should meet (all else being equal) if one's execution of the strategy is to be successful. In section 2.1, I lay out the first of Nichols' accounts, which I call the Deductivist Account. In section 2.2, I argue that the limited psychological data proffered in support of a key premise in the Deductivist Account fails to justify accepting the key premise; in section 2.3 , I raise several objections to this account, including the charge that it fails to meet Spinozan Strategy adequacy conditions, even if the key premise is granted for the sake of argument. In section 3.1, I lay out Nichols' other account, which I call the Probabilistic Account. In section 3.2, I argue that this latter account faces many of the same objections as the Deductivist Account, even after attempts at friendly amendment. I conclude in section 4 by mapping the remaining terrain available to Spinozan strategists who seek to avoid running afoul of their own adequacy conditions.

\section{Setting the Stage}

In considering why people might think they have free will, Baruch Spinoza famously wrote:

Men believe themselves to be free, simply because they are conscious of their actions and unconscious of the causes whereby those actions are determined (2005, IIp2s). 
According to Spinoza, we are not aware of any determining causes of our actions, and so think ourselves free on those grounds. Spinoza puts the point in terms of belief in freedom, but the quotation outlines a strategy that, with appropriate modifications, yields a strongly analogous approach to explaining belief in indeterministic choice. Putting the point in terms of indeterministic choice gives rise to the Spinozan strategy. The Spinozan strategy starts by denying that we experience our choices as indeterministic. Rather, it holds that we lack experiences of choice as being causally determined. The widespread belief in indeterministic choice is then inferred from this dearth of experiential evidence for the causal determination of choice. The challenge for the Spinozan strategist is to provide a satisfactory account of this inference.

A first prima facie worry for this strategy is that the inference seems to involve a kind of scope fallacy, whereby people take the absence of evidence as evidence of absence. While inferring evidence of absence from an absence of evidence is not always bad, it requires further background assumptions if the inference is to be even remotely reasonable. Spinozan strategists attempt to provide the background assumptions necessary to bridge this gap (Holton 2009, 2011; Nichols, 2015; Horgan, 2011a; Dennett, 1984; Magill, 1998). Prominent examples of Spinozan strategists include Daniel Dennett, who writes of decision-making:

We see the dramatic effects leaving; we don't see the causes entering; we are tempted by the hypothesis that there are no causes. The invisibility of causal paths is not just a matter of the invisibility (to us) of other minds. From our own first-person 'introspective' vantage point the causal paths are equally untraceable (1984, pp. 77-8).

Richard Holton argues similarly: 
It is easy to see ... how the experience of choice could be mistaken for the experience of one's actions being undetermined: one is mistaking a local claim of one's non-determination (one's action is not determined by one's prior beliefs, desires and intentions) for a global one (one's action is not determined by anything) $\left(2009\right.$, p. 171). ${ }^{2}$

Again, in a similar vein, Sean Nichols writes:

[A]ssume that people know that what is introspectively accessible doesn't fix a decision. If people also presume that they have access to the proximal influences on their decisions, then they would have the materials to draw the reasonable inference to indeterminism (2015, p. 42).

These philosophers all agree that we come to believe our choice is indeterministic on the basis of an absence of an experience of choice being causally determined.

We might contrast the Spinozan strategy with the straight strategy. According to the straight strategy, we do experience our choices as causally undetermined and thereby come to believe, on the basis of such experience, that choice is not causally determined (Searle, 2003, p. 270; O’Connor, 1995, p. 200; Swinburne, 2014, pp. 201-2). Thus, to the extent that inference is involved at all, the inference is a straight one, in the sense that the contents of our experiences and our beliefs about choices are much the same - they both represent choice as indeterministic. This sort of explanation has been particularly attractive to libertarians, who further argue that the belief is justified and provides support for libertarianism (Campbell, 1967; O’Connor, 1995; Pink, 2004; Mawson, 2011; Swinburne, 2014).

\footnotetext{
${ }^{2}$ Nichols considers himself to be arguing the same line as Holton, though they do seem to describe the experiences slightly differently. However, both agree that indeterminism, full stop, is not part of the content of the experience of choice.
} 
Non-libertarians have been surprisingly reluctant to endorse the straight strategy. This is curious given that non-libertarians, including compatibilists, hard determinists, and hard incompatibilists, could avail themselves of the strategy with minor addendums. For example, compatibilism holds merely that free will is compatible with determinism. It does not further require that determinism be true. In which case, one might maintain that determinism is false and compatibilism is true, and accept the widespread belief in indeterministic choice. Indeed, even if one is a compatibilist committed to the truth of determinism, like Hobbes or Hume, one might still accept the straightforward explanation; it would only require that the experience of indeterministic choice be an illusion (Smilansky, 2000; Sommers, 2007; Caruso, 2015).

Hard determinists, who think determinism holds and rules out free will, and hard incompatibilists, who think free will is impossible regardless of the truth of determinism, can similarly avail themselves of the straight explanation with no apparent threat to their views. In the case of hard determinism, they need only point out that experience is an illusion. For the hard incompatibilist, either the experience is an illusion, or experience provides some prima facie evidence to think that the world is indeterministic. Either way, the hard incompatibilist can still maintain that free will is impossible. The straight strategy, then, seems independent of one's commitments in the free will debate.

Despite these options, numerous non-libertarians have pursued the Spinozan strategy (Holton, 2009; Deery, 2013; Horgan, 2011a, 2011b; Magill, 1998; Dennett, 1986; Nichols, 2015). They seem to balk in particular at the kind of raw experience of indeterminism invoked by the straight strategy. Normally this commitment is based on personal introspection, where philosophers find themselves unable to find any experience of indeterministic choice (Doris, 2016, p. 167; Smilansky, 2000, p. 59; Horgan, 2011a). However, one might also argue that an 
experience of indeterminism more generally outstrips the possible bounds of experience. As Holton puts it, '[I]t is hard to think what an experience of that [indeterminism] would feel like. It is too theoretically loaded' $(2009$, p. 168). In rejecting the phenomenological claim, these philosophers must reject the straight strategy as well.

In addition to rejecting this phenomenological claim, the Spinozan strategy is routinely accompanied by a set of adequacy conditions. Like many explanatory desiderata, these conditions often remain implicit in the structure of the debates and arguments contained therein. Further, these conditions are perhaps most plausibly construed as defeasible and ceteris paribus. For all that, I maintain that the following (no doubt incomplete) list of adequacy conditions is both reasonable and prevalent in much recent work by Spinozan strategists:

A. Scientific Plausibility: One's explanations of folk beliefs should be plausible in light of our best extant science.

B. Reasonableness: All else being equal, to the extent an explanation of folk belief avoids the attribution of obviously unreasonable inferences, it is to be preferred over those that attribute less reasonable inferences.

C. No Overgeneralization: Explanations of folk beliefs ought not to overgeneralize.

Let me say a bit more about each of these conditions.

Scientific Plausibility. All else being equal, the explanation of the belief in indeterministic choice ought to be psychologically plausible (Searle, 2003; Dennett, 1984, p. 15; Nichols, 2015, p. 49). This should not be contentious. The Spinozan strategist makes empirical claims, so we ought to check them against our best empirical data. This need not require that the account be fully supported by psychological data. Indeed, there is a general attitude of 
speculation and armchair psychology involved in these accounts. Nevertheless, to the extent that one's account is supported by our best extant science, it is preferable to merely possible, speculative accounts. If our best scientific picture of decision-making conflicts with widespread experiences and beliefs, then explaining away these experiences and beliefs becomes all the more pressing. ${ }^{3}$

Reasonableness. This condition calls for a minimal kind of reasonableness. The condition is not that the belief be true, or that the grounds for endorsing it be reasonable, or even that these grounds be prima facie reasonable. For that matter, it does not even impose the demand that attributions of unreasonable inferences are categorically impermissible. Rather, the claim is merely that, all else being equal, we should prefer explanations of folk belief that avoid characterizing a belief's source as obviously unreasonable (Dennett, 1986, Ch. 1; Nichols, 2015, p. 48; Holton, 2009, p. 171).

Belief in libertarian free will, and so indeterministic choice, is widespread and apparently cross-culturally robust. ${ }^{4}$ In view of this, there are two independent motivations for insisting on Reasonableness. The first motivation is relevant to explaining the apparent entrenchment of belief in indeterministic choice. If the source of belief in indeterministic choice were obviously unreasonable, it would be hard to see why the belief would be so widespread. Further, it would be hard to explain why it is so apparently recalcitrant to reflection. After all, in the history of philosophy, many highly influential thinkers have perseverated in their belief despite protracted periods of reflection on such matters. The point is not that explanations of entrenchment that

\footnotetext{
${ }^{3}$ Many philosophers take the studies of Libet (1983), Wegner (2002), and Soon et. al. (2008) as supporting models of choice that conflict with experience.

${ }^{4}$ Sarkissian, 2010. Although I find the initial evidence intriguing, the evidence is admittedly in its infancy, and work by Nahmias and Murray (2010) may provide some pushback. In eastern traditions such as Buddhism and the Samkhya school of Indian philosophy, the idea that agents are independent, original causes of action is presented as an illusion. This suggests they are presenting an alternative to the widespread view, reinforcing the idea that beliefs in a libertarian spirit may not be unique to the Western philosophical tradition.
} 
violate Reasonableness are impossible. (What would an argument for such a claim look like?) Rather, the point is that entrenchment appears far easier to explain if one supposes the absence of obvious unreasonableness, and to that extent Reasonableness should be the default.

The other motivation for insisting on Reasonableness is a minimal notion of charity. In philosophical practice more generally, it is best to interpret your interlocutor as making rational inferences. There are numerous examples of charitable principles in philosophy (Davidson, 1984; Quine, 1960). Preferring explanations that are not obviously unreasonable falls out of even the most minimal characterization of charity. The point is not that charity requires that belief in indeterministic choice be rational, but rather that even the most minimal accounts of charity prefer attributing not obviously unreasonable inferences to others.

No Overgeneralization. Prohibitions on overgeneralization are a normal component of any good explanation. It counts against the acceptability of a purported explanation if the explanation predicts phenomena in places where they do not occur. What's true generally holds in the present case. If the Spinozan strategy predicts indeterministic beliefs where people do not hold them, this counts against the Spinozan strategy.

The Spinozan strategy is particularly susceptible to overgeneralization worries. The lack of an experience of causal determinism is not at all unique to the experience of choosing; I doubt that even paradigmatically causally determined events, like sunrises, are experienced at the time as causally determined. And yet, unlike belief in indeterministic choice, people do not infer indeterminism from a lack of an experience of determination in any other cases. No one is going around suggesting headaches are indeterministic, yet headaches are not accompanied by experiences of determination. 
The specter of overgeneralization is of primary concern to the Spinozan strategist. Shaun Nichols expressly designs his account to address the overgeneralization worry that afflicts other Spinozan strategists. He points out, '[I]gnorance of the causes of these phenomena does not generally breed the belief that the phenomena aren't determined. So even if Spinoza is right that we are ignorant of the causes of our actions, that doesn't yet explain why we believe that our actions aren't determined' $(2015,38)$. The challenge for the Spinozan strategist is to posit background assumptions that explain the indeterministic belief in the case of choice, but also explain why there is no indeterministic belief in other cases. This is not a detail to be worked out later by psychologists. It is core to the success of the Spinozan strategy.

Filling in the Spinozan Strategy, then, involves explaining the move from a lack of an experience of the causal determination of choice to the belief in indeterministic choice that does not overgeneralize (No Overgeneralization) while invoking inferences on the part of the folk that are not obviously unreasonable (Reasonableness) and are plausible in light of our best extant science (Scientific Plausibility).

Although not a condition of adequacy, I would like to flag one final feature of the Spinozan strategy before moving on to Nichols' accounts. As we have seen, the Spinozan strategist seeks to explain the widespread belief that choice is indeterministic. Yet in doing so, they invariably ignore another apparently widespread, and closely related, belief - one that, all else being equal, we should also wish to explain. People do not merely believe that their choices are indeterministic; they seem to believe that they experience their choices as indeterministic (Deery et. al., 2013; Deery, 2015). These studies found that, after making a choice, participants tended to agree that they experienced that they 'could have done otherwise' in a way that is incompatible with causal completeness (Deery et. al., 2013, p. 138, $M=5.60$ ). In informal polls 
of undergraduates, many philosophers find that their students tend to describe their phenomenology in indeterministic terms (Holton, 2010, pp. 86-7). While the empirical evidence here is admittedly in its infancy, it provides early support for an assumption that has long been held among philosophers and non-philosophers: people tend to describe their experiences of choice using indeterministic terms.

Plausibly, the straight strategy has no special problem explaining this fact; we routinely take ourselves to believe that our experiences are a specific way precisely because they are that way. I believe, for example, that I am having an experience as of a red rose, precisely because I am having an experience as of a red rose. Reasonably enough, straight strategists ask why the experience of indeterministic choice should be any different (Pink, 2004). That is, why not think we believe that we experience choice as indeterministic simply because we do experience choice as indeterministic?

In contrast, it is not at all obvious what the Spinozan strategist should say in order to explain this belief about experience. The suggestion, in short, is that where Spinozan strategists typically see one belief in need of explanation, there are in fact two: the belief that choices are indeterministic, and the belief that we experience our choices as indeterministic. In what follows, I focus largely on the former belief, although I will return to the latter towards the end of the article.

\section{How Possibly Story 1: The Deductivist Account}

\subsection{The Account}

Nichols offers two different "how possibly" stories that attempt to fill in the Spinozan strategy so as to avoid overgeneralization. I will take each in turn. I call the first account the 
Deductivist Account. Nichols presents the Deductivist Account (DA) in the following argumentform:

D1) The [proximal] factors that are introspectively accessible do not determine my choice.

D2) I have introspective access to all the (proximal) factors that influence my choice

D3) My choice is not determined (Nichols, 2015, p. 42)

The idea is that, if the folk believed (D1) and (D2), then they would have an apparently valid argument which would support the belief in indeterministic choice. Nichols' core task, then, is to support the claim that people actually do believe (D1) and (D2)

Nichols thinks that his libertarian opponents already agree that (D1) is largely accepted, so he thinks the real action is with premise (D2). If there was widespread belief in (D2), according to Nichols, then a good explanation of why (D2) is accepted by the folk would provide a Spinozan strategy explanation that is complete without overgeneralizing. Such an explanation would not rest on an experience of indeterminism and would comport with our best science (Scientific Plausibility). Furthermore, because we assume that introspection reveals all of the proximal influences contributing to choice, the fact that introspection does not reveal choice to be causally determined also supports the belief that nothing causally determines choice. Thus, the inference from introspective experience to belief is not obviously unreasonable (Reasonableness). Finally, it is because we believe we have introspective access to all of the proximal influences in the case of choice, but not in the case of headaches, that we believe choices are indeterministic but not headaches (No Overgeneralization). Thus, an explanation of 
the belief in (D2) provides a complete explanation that doesn't overgeneralize. Or so the story goes.

While (D2) may appear fairly benign, it is worth stressing that it is quite a strong commitment. The Deductivist Account is most naturally read as a person-level explanation of the widespread belief in indeterministic choice. So (D2) is naturally read as a person-level folk belief. Further, if (D2) is to justify accepting the claim that choice is causally indeterministic (as the Spinozan strategy requires), then (D2) must assume introspective access to the explicitly causal features of the proximal factors influencing my choice. Finally, even if none of the proximal factors influencing my choice is an individually determining cause of my choice, the factors could jointly be a deterministic cause of my choice. So, in order for (D2) to justify the belief that choice is indeterministic, it must be construed as implying introspective access to the interactions among these influences as a collective causal system as well. ${ }^{5}$

As Nichols clearly recognizes, he cannot merely stipulate that (D2) is endorsed by the folk. This would render the proposal empirically unwarranted, and would also succeed only in pushing the overgeneralization worry one stage back. In view of this, he provides a two-staged response. First, he invokes survey-style experiments from Kozuch and Nichols (2011) to argue that people do in fact accept (D2). Second, he draws heavily on Leonid Rozenblit and Frank Keil's research on the illusion of explanatory depth (IOED), both to explain the (putative) widespread acceptance of (D2), and to avoid overgeneralization worries (Nichols, 2015, pp. 44-

\footnotetext{
${ }^{5}$ This point will be important when discussing the empirical support for (D2). One potential way of expanding this point is to consider the properties of the system as a whole. See Wimsatt (2006) for a helpful discussion of potential criteria for system properties as opposed to merely aggregative properties.
} 
5). ${ }^{6}$ In what follows, I explain what IOEDs are and their proposed role in the Deductivist account. I then argue that neither stage of Nichols' response is satisfactory.

IOEDs occur when an individual mistakenly believes they have a deeper understanding of a particular phenomenon than they in fact do (Rozenblit and Keil, 2002; Lawson, 2006; Mills and Keil, 2004). In particular, IOEDs occur when causal interactions in mechanisms that are easily available to perception are mistakenly taken to provide a deep causal explanation of the mechanism. In one experiment, for example, subjects were asked to rate their confidence that they understood how simple mechanisms work- e.g. locks and zippers. Initially, subjects consistently rated themselves quite highly. But when subsequently asked to provide a written explanation, people systematically downgraded their confidence ratings; and then downgraded again when presented with expert explanations of the mechanisms. This downgrading of confidence ratings when faced with the inadequacy of their own understanding is the hallmark of IOEDs.

As Nichols suggests, it seems possible that we could be subject to an IOED when considering our own choices. When we introspect the factors leading up to our own choices, we plausibly find discrete causal states (thoughts, intentions, etc.). We 'see' these discrete states interacting in much the way we see causal states within a physical mechanism. We use this introspection to explain and make accurate predictions about what we will do. We almost never receive information suggesting that introspection in these cases is misguided. Thus, we could be subject to an IOED in the case of choice. If we were subject to an IOED in the case of choices, then (D2) would seem like a plausible assumption to adopt.

\footnotetext{
${ }^{6}$ The term "illusion of explanatory depth" here is a technical term and should not be confused with the more general notion of an illusion akin to having a false belief.
} 
Nichols thinks the IOED hypothesis explains why the folk might endorse (D2). It also provides a way to block the overgeneralization problem. If we are subject to an IOED in the case of choice, but not other psychological phenomena, like headaches, then we would not assume the analog of (D2) for headaches and the like and, hence, would not endorse indeterminism about such phenomena. According to Nichols, in the absence of an IOED:

$[\mathrm{T}]$ here is no presumption of broad-scale access to the causally relevant factors in the generation of headaches. As a result, there is no basis for drawing indeterminist conclusions about headaches from the fact that we can't detect a deterministic set of causes (2015, p. 46).

Thus, the Deductivist Account promises to furnish us with an elegant explanation of widespread folk indeterminism about choice. The widespread folk acceptance of (D2) helps explain indeterminism about choice; the presence of an IOED for choice explains this widespread acceptance; and the absence of an IOED for most other psychological phenomena addresses the overgeneralization problem.

Unfortunately, this apparently elegant explanation is subject to serious objections. First, there is no good reason to suppose that the folk actually accept (D2) - or, at any rate, not a version sufficiently robust to do the work required of it by the Deductivist Account. Moreover, even if widespread belief in (D2) were assumed, IOEDs fail to provide a satisfactory explanation of this putative fact.

\subsection{Concerning the Folk Acceptance of (D2)}

Prima facie, the assumption of (D2)'s widespread acceptance is implausible. When pressed about one's choices, 'I don't know why I did that', and its cognates are perfectly 
felicitous utterances in English, sincerely asserted on a seemingly regular basis. Further, we live in a post-Freudian world where the knowledge that there are unconscious influences on behavior is a pervasive aspect of popular culture. It would be surprising if this knowledge had no impact whatsoever on intuitive judgments about choice. Nevertheless the issue is, of course, an empirical one; and despite these prima facie considerations to the contrary, it may really be the case that (D2) is widely accepted.

My main concern, however, is the paucity of empirical support for this contention. To my knowledge, there is exactly one study that purports to bear directly on the matter - the series of experiments found in Kozuch and Nichols (2011). But contrary to what Nichols suggests, this study provides little or no support for folk acceptance of (D2).

Although Kozuch and Nichols (2011) present a series of five experiments, only Experiment 2 investigated the extent to which people assume introspective transparency to their own decision-making, and for this reason, I focus my criticisms on that experiment. ${ }^{7}$ In Experiment 2, Kozuch and Nichols asked participants the extent to which they agreed with the following prompt:

When I am making a decision about what to do (for example, deciding whether to go swimming), if I pay attention to my thought processes, I can usually see what leads me to make the decision I do (p. 146). ${ }^{8}$

Participants marked their agreement on a 1-7 Likert scale. Agreement with this statement was high, $(M=5.47$, S.D. $=1.36)(146)$. Kozuch and Nichols compared this to agreement in cases

\footnotetext{
${ }^{7}$ Although I address my criticisms to experiment 2, my worries about the causal interpretation of the probe statements apply to the other experiments as well, mutatis mutandis.

${ }^{8}$ Kozuch and Nichols acknowledge that there are some concerns with this kind of explicit-measure testing. Additionally, there was at least one instance where half of the participants failed comprehension checks. While these methodological worries are concerning, my ultimate rejection of Kozuch and Nichols' conclusions do not depend on them. See Sommers (2015) for more general methodological worries about the course of experimental philosophy in the free will debate.
} 
where the statements were largely the same but 'making a decision' was replaced by 'feeling an urge'.

When I am feeling an urge to do something (for example, deciding whether to go swimming), if I pay attention to my thought processes, I can usually see what leads me to feel the urge I do (p. 146).

Participants showed agreement with this statement as well, $(M=4.69$, S.D. $=1.35)($ p. 146). However, since there was greater agreement in the case of decisions than urges, Kozuch and Nichols take general agreement with the statement, '...I can usually see what leads me to make the decision I do,' (Em. Added) as evidence for the claim that the folk believe they, '.... are usually able to know the causes of their decisions as opposed to urges (p. 146).' It is this result which, according to Nichols, supports the contention that the folk accept (D2) but not analogous claims for urges and other psychological phenomena.

I have four main concerns regarding the use of Kozuch and Nichols' study in developing the Deductivist Account. First, although there is greater agreement in the case of 'making a decision' than 'feeling an urge', there is nevertheless agreement with the probe statements in both cases. Indeed, in both cases, the mean is far above the midpoint on the Likert scale. But if this is so, then it is hard to see how the data could support (D2), without also providing significant support for an analogous assumption regarding urges. ${ }^{9}$ And if this is so, then Nichols would appear to have lost his response to the overgeneralization problem since it is by denying that the folk endorse such analogous assumptions that he seeks in order to resolve the overgeneralization problem.

\footnotetext{
${ }^{9}$ Kozuch and Nichols insist that despite agreement in both cases, there is a statistically significant difference in the degree of the effect between the two cases. While this may be true, it would only suggest that (D2) analogues would be slightly weaker than (D2).
} 
Second, if Kozuch and Nichols' study is to support the claim that (D2) is widely endorsed, one must adopt a causal interpretation of expressions like 'leads me to decide'. This is because 'influence' in (D2) must mean causal influence. Yet expressions like 'leads me to decide' are clearly amenable to alternative non-causal readings. In particular, when agreeing that I can 'usually see what leads me to make the decision I do', I may be agreeing that I appreciate the reasons that speak in favor of performing an action, without interpreting those reasons as causes of my choice. My point is not, of course, that we must interpret the probe statements in this way. Rather, the point is that nothing in the data militates against such a reading, and in favor of a causal interpretation. Further, the idea that such locutions are amenable to non-causal construals is hardly without precedent, either in the philosophy of action or, more recently, in empirical research on folk judgment. For example, Knobe (2014) defends what he calls the transcendence vision, on which choices are viewed by the folk as being made 'on the basis' of prior mental states, but not necessarily caused by them (p. 70). On such a view, I may know the reasons that 'lead me to make the decision I do' without necessarily equating those reasons with the causes of my choice. ${ }^{10}$ Instead, they could 'lead me' to make a decision by providing a rationalization of my action. In light of interpretations like those suggested by the transcendence vision, the causal interpretation of the probe questions adopted by Kozuch and Nichols is in need of far more support.

Third, even if we concede a causal interpretation of the probe statements, the putative evidence would still fall far short of supporting (D2). (D2) asserts that I have introspective access to all the proximal factors that influence my choice. But mere agreement with the claim that I can generally 'see' what causes my decisions in no way suggests such a view. Even on a

\footnotetext{
${ }^{10}$ This is not meant to refute the claim that reasons are causes, as argued for in Davidson, 1963. Rather, it merely suggests that the folk concept of reason may come apart from the folk concept of a mere cause, a point defended in Malle, 1999 and Malle et. al., 2007.
} 
causal interpretation, agreement might indicate no more than the judgment that I have access to a contextually salient cause of my decision. That is, I might think I have access to some - even the - contextually salient difference maker, without thereby thinking I have access to all the proximal influences. By way of analogy, consider a case where I take myself to know the cause of an explosion -e.g. that the bomb fuse was lit. Under such circumstances, I may legitimately think I know what caused the bomb to explode without thereby supposing that I have access to all the proximal influences that brought about the explosion. Mutatis mutandis for decisions. In short: while a causal interpretation of the probe statements may help support some vague assumption of transparency, it does not support the stronger contention that (D2) is widely held by the folk.

Finally, given the above, Kozuch and Nichols' study fails to support the presumption, implicit in (D2), that people think all (proximal) influences on choice are introspectively accessible mental phenomena. This is because the probe statements in their experiments are formulated so as not to require participants to make any assessment regarding the influence of non-introspectable factors. More specifically, by incorporating the phrase '...if I pay attention to my thought processes...', the probe statements only prompt participants to reflect upon whether they have access to aspects of the thought processes that lead to their decisions. But the mere fact that people tend to agree that they can usually tell what aspects of mental processes lead to their decisions, in no way implies that they deny the existence of additional, non-mental - hence non-introspectable - influences. For they might think that introspectable mental phenomena and non-introspectable phenomena influence decisions. ${ }^{11}$ As a result, the Kozuch and Nichols' study

\footnotetext{
${ }^{11}$ It strikes me as relatively easy to test whether people accept that non-introspectable factors influence choice. One option would be to run experiments quite similar to Kozuch and Nichols' own, but where the probe statements concern the influence of extra-mental factors. For example: 'When I am making a
} 
fails to support the contention that folk thinking about our own decision-making is typically restricted to introspectively accessible mental events.

\subsection{Objections to the use of IOEDs in the Deductivist Account}

In the previous section I argued that there is little empirical support for the widespread acceptance of (D2), and what support is offered by Nichols requires an unmotivated, strongly causal interpretation of the probe statements. But even if we grant for the sake of argument that (D2) is widely held, Nichols' use of the IOED literature is problematic.

According to Nichols, we are subject to an IOED in the case of choices, but not other mental events, because only in the case of choices do we identify plausibly discrete causal states via introspection. But it is hard to see why one would think that such prior causal states are present only in the case of choices. Why not, for example, in the case of headaches as well? Thinking hard about the intricate details of the IOED literature is extremely taxing, and could plausibly play a causal role in my incurring a headache. External stressors and noises certainly seem to play some causal role in bringing about headaches in normal conditions. I have stared at sheet music while drumming loudly and felt the slow onset of a headache. The strain of focused visual attention and pounding noise in these cases are surely proximal causes if ever there were any. If Nichols' theory predicts an IOED in the case of choices on the basis of the reflective availability of prior discrete causal states, then it ought to predict an IOED in the case of headaches as well, and so predict an analogue to (D2) in the case of headaches. So, Nichols has not avoided overgeneralization. One of the main demands on his theory fails. 
One might respond to the above criticism by arguing that many of the discrete causal states I appeal to in the hypothetical reflection on the etiology of headaches are not introspectable mental states. In the case of headaches, but not choices, we look for causes outside of the head. The Deductivist Account thus avoids overgeneralization because (D2), the premise that I have introspective access to all the (proximal) factors that influence my choice, is restricted to introspectable mental states, and so seems plausible in the case of choices, but an analogous principle in the case of headaches does not.

This response misses the point. We have already granted that (D2) is widely accepted for the sake of argument. The purpose of introducing IOEDs is to explain why people might accept something like (D2) in the case of choices but not in other cases. If the resources that justify positing an IOED in the first place, i.e. access to plausibly discrete causal states, are available in the case of headaches as well as choices, then IOEDs do not provide an adequate response to the overgeneralization worry.

Putting the previous objection to one side, let us grant for the sake of argument that there is an asymmetry between choices and headaches that justifies thinking there is an IOED in the former case but not the latter. Even granting that IOEDs resolve the overgeneralization problem, it is hard to see how to develop the account without running afoul of Reasonableness or Scientific Plausibility.

On its most simple interpretation, the Deductivist Account fails Reasonableness because it attributes inconsistent beliefs to the agent. Specifically, it requires that they think their choices are both deterministic and indeterministic. As Rozenblit and Keil explain, IOEDs occur when we '...mistake shallow, sparse lay theories of mechanism for deep rich ones (2002, p. 23), in providing a causal explanation of the phenomena. They cite Ahn and Kalish (2000), who write 
of causal explanation, 'If A causes B, then A makes B happen: B had to happen given A. It was no accident. It is this sense of necessity that distinguishes "real" causal relations from "mere" correlations (pp. 200-1).' The lesson: if the phenomenon is not viewed as a causally deterministic mechanism, then there tends not to be an IOED. ${ }^{12}$ Rozenblit and Keil's results support this lesson. IOEDs occurred in the case of devices with clearly visible mechanisms, like zippers and crossbows. In the case of non-devices, such as procedures for folding flags and narratives, IOEDs did not occur (Rozenblit and Keil, 2002, p. 26). ${ }^{13}$ If we are to understand IOED's in anything like the way that Rozenblit and Keil themselves do, then we should suppose that they arise against a background of assumptions whereby the target system is construed as a deterministic mechanism.

In view of the above, if an IOED is to explain the widespread acceptance of (D2), then that involves subjects construing the target system (in this case, mechanisms of choice) as deterministic ones. But this assumption is prima facie inconsistent with the conclusion (D3), that choice is not determined! If IOEDs do underlie the belief in indeterministic choice, then it would appear that we believe the systems which generate choices are both deterministic and indeterministic. It may well be that we hold inconsistent beliefs regarding our choices, but this apparent inconsistency constitutes a threat to Reasonableness.

Attempts to ameliorate this apparent inconsistency face a dilemma: either the account fails to adequately explain the phenomena, or the account fails the demand for Scientific

\footnotetext{
${ }^{12}$ Nichols could reject this aspect of the Rozenblit and Keil account. However, doing so would come at a cost. This aspect of the account is driven by a pattern in the empirical data, namely: people tend to exhibit IOEDs in the case of (apparently deterministic) mechanisms, and yet fail to exhibit IOEDs in the case of other apparently causal phenomena. If we give up this aspect of the Rozenblit and Keil account, we lose an explanation of why the data exhibits this pattern. Thank you to an anonymous referee for raising this point.

${ }^{13}$ Studies 1-4 indicate an IOED for devices, while Study 10 indicates a smaller IOED for natural phenomena (e.g. earthquakes). While the difference in results for devices and natural phenomena were not significant, they did trend towards significance, with the IOED greater in the case of devices. Of special interest are studies 8 and 9 where no IOED occurred.
} 
Plausibility. Suppose the assumption that influences on choice constitute a deterministic causal mechanism were discharged upon accepting (D3), as in a reductio ad absurdum argument. This proposal would meet the Reasonableness demand, but fail to adequately explain the phenomena. For if we discharge the deterministic assumption, then were we to introspect the proximal influences on our choices at some future time, we would not be subject to an IOED. And if we were not subject to an IOED, then we would no longer accept (D2). In which case, we would not accept the conclusion, (D3), that choice is not determined. Discharging the deterministic assumption thus fails to explain the fact that we perseverate in our belief in indeterministic choice.

The alternative proposal is to hold that we do have a long-term commitment to conflicting beliefs about the determinacy of choice, but to argue that, depending on how one understands 'reasonable', this conflict need not threaten Reasonableness (Sloman and Barbey, 2016). Of course, the mere fact that one holds inconsistent beliefs is not sufficient to count an individual as unreasonable. Nevertheless, I take it to be fairly uncontroversial that if one believes that choices are both deterministic and indeterministic in the context of a single piece of reasoning, then the inference is prima facie unreasonable. The inference, as it were, wears its unreasonableness on its sleeve.

Still, the beliefs that choice is both deterministic as well as indeterministic could be compartmentalized from each other, or we could make one (or more) of the beliefs sub-personal in an attempt to massage away the apparent unreasonableness. Both these moves embed the belief in our cognitive architecture in a way that prevents us from revising (D2) upon reflection. This in turn could explain the perseveration of belief in (D2) while also allowing subjects to discharge the deterministic assumption. 
The above proposals would extend far beyond what is empirically supported by the IOED literature. Recall, a signature property of being subject to an IOED is that the agent downgrades their confidence upon further reflection. Yet the above proposals specifically hold that such downgrading does not occur. In which case, we will have lost much of the scientific plausibility there was for invoking IOEDs in the first place. The present proposals, then, while admittedly possible, no longer meet the demand for Scientific Plausibility. ${ }^{14}$

\section{How Possibly Story 2: The Probabilistic Account}

\subsection{The Account}

Nichols provides an alternative to the Deductivist Account that relies on methods common in probabilistic learning models to explain the inference from the absence of evidence to the evidence of absence. I call this account the Probabilistic Account. In the Probabilistic Account the inference from the experience of choice to the belief in indeterministic choice is an induction based on probabilities.

To illustrate, consider a case where a friend shows you two decks of cards: one is a fair deck and the other contains only black cards. Your friend then removes one of the decks (you don't know which one) and destroys it. You draw a card from the remaining deck, reveal its color (red or black), return the card to the deck and shuffle, and then repeat the process. Suppose after 100 draws you have only turned up black cards. There are two possible hypotheses to explain this string of black cards. Either the deck is fair and you have had an unlikely run of draws, or there are more black cards in the deck than red cards. It seems reasonable to believe, in light of 100 straight black draws, that the deck is in fact not a fair deck. The fact that you do

\footnotetext{
${ }^{14}$ It is worth further exploring how compartmentalized/ encapsulated closed world assumptions like (D2) could enter into an explanation of the belief in indeterministic choice that meets Spinozan strategy commitments. Thank you to an anonymous referee for pushing this point.
} 
not turn up a red card leads you to believe that this is the all-black deck. ${ }^{15}$ Each draw without a red card your confidence that the deck does not have red cards. The Probabilistic Account uses similar reasoning. Here's how Nichols presents it:

The class of decisions we'll focus on are 'difficult decisions' . . like Buridan's ass cases . . For each of those decisions, the agent has knowledge of a set of mental states that influences his decisions ... The set of states of which he is aware does not provide a deterministic explanation of his decision. Given the relevant evidence that he does have (i.e., evidence of the influence of sets of states) and the evidence that he doesn't have (i.e., evidence of sets of states that determine his decision), the agent infers that difficult decisions are not deterministically produced $(2015,48)$.

Nichols admits that a great deal must be assumed for this to work. It restricts to a class of decisions, it assumes the accessible states do not provide a deterministic story, it assumes that there is reason to think that absence of evidence is evidence for absence, and it assumes the set of sets, and the mental states within each set, are a random and representative sample. This final assumption is of particular importance. It is designed to rule out the possibility of selection bias. That is, it is meant to rule out the possibility that there is a potential influence on choice that, due to the sampling mechanism, consistently slips through the cracks. ${ }^{16}$

Here I present my attempt to summarize, in premise form, the Probabilistic Account.

P1) For a class of choices (of which I have made many), I have knowledge of a random and representative sample of mental states that influence the choices in that class.

\footnotetext{
${ }^{15}$ According to Bayesian reasoning, each additional draw without a red card should make you more confident this is the unfair deck. For further discussion of Bayesian probabilistic reasoning models, see Tenenbaum et. al., 2006.

${ }^{16}$ Sober (2009) uses the analogy of a fish net with holes so large that fish under a certain length are never caught.
} 
P2) The samples of mental states of which I am aware do not provide a deterministic explanation of my choices.

P3) The fact that I lack evidence that there are deterministic causes of these decisions provides probabilistic evidence that these decisions are not determined. ${ }^{17}$

In order to reason this way, one need not assume access to all of the mental states that influence choice. However, it does assume that the mental states to which one has access are a random and representative sample of the total choice-influencing mental states. ${ }^{18}$

\subsection{Objections to the Probabilistic Account}

It is unclear from Nichols' presentation whether the sample of mental states of which I am aware in $(\mathrm{P} 1)$ is a subset of the total mental states influencing a given choice, or the complete set of proximal influences on a given choice, which is itself a sample of a wider class of choices. As I will show, both interpretations face problems.

On the first interpretation of $(\mathrm{P} 1)$, we can introspect a random and representative sample of causally influential mental states to see if they determine a choice, and then infer that the total set of causally influential mental states did not determine the choice. This involves viewing the mechanism of choice as what Richard Levins calls an 'aggregate system'. In aggregate systems, properties of the whole are statistics of the properties of individual parts of the system (Levins, 1970, p. 76). In 'composed systems', in contrast, the properties of the whole depend on the specific ways in which their component parts are combined. In composed systems, you cannot

\footnotetext{
${ }^{17}$ Adapted from Nichols, 2015, pp. 48-49.

18 The success of the Probabilistic Account also depends on the assumptions that (i) you focus on a restricted set of decisions (he uses difficult decisions), (ii) that you never actually experience this set as determined, and (iii) your introspection actually reveals evidence of the absence of causal determinism. While these are all potentially problematic, in this article I focus only on the random and representative aspects.
} 
make justifiable statistical inferences from parts to wholes because the interactions between parts are crucial to the properties of the whole, and these interactions are not necessarily identical.

The problem for the Probabilistic Account is that the psychological processes leading to choices look more like composed systems than aggregate systems. Suppose I want to know whether a long argument with many premises is valid or not. It is not enough for me to take a random and representative sample of the premises in order to check whether the argument as a whole is valid. The problem is that validity involves the relationship between sets of premises and a conclusion, not between individual premises and a conclusion. Sampling individual premises, or even subsets of premises, doesn't tell us enough about the set of premises as a whole and its relation to the conclusion. Likewise, sampling a subset of the many mental states that speak in favor or against a particular choice doesn't tell us enough about the relationship between the mental states taken as a whole and its relation to the choice to justify inferring (P3).

It could be argued that the relevant hypothesis for the Probabilistic Account is that for some choices, introspection reveals a complete set of proximal mental states. ${ }^{19}$ This is to adopt the second interpretation of $(\mathrm{P} 1)$. Because the sample is just the complete set of proximal mental states, there is no concern about the sample failing to reflect properties of the composed system as a whole. This move, however, collapses the Probabilistic Account into the Deductivist Account. The problems that were raised for (D2) now re-arise. It requires that for any given choice, we assume to have access to the explicitly causal features of a complete set of proximal influences, but there is little evidence that we accept such a strong principle.

Although these interpretative problems are worrisome, there is a further problem for the Probabilistic Account: it fails to accommodate No Overgeneralization. One reason for Nichols' optimism with regards to the Probabilistic Account largely comes from the fact that we have

\footnotetext{
19 Thanks to Shaun Nichols for pointing out this possibility.
} 
good evidence that human beings learn using probabilistic inferences more generally. In fact, models that invoke probabilistic inference making are pervasive throughout cognitive science (Tenenbaum, 2007; Gerken, 2010; Romberg and Saffran, 2010; Denison, Reed and Xu, 2013). Yet this proliferation of probabilistic explanations also suggests that the overgeneralization worry may once again be around the corner. If we already have good reason to think that probabilistic inference is going on in other domains, then why don't we see belief in indeterminism popping up in those other domains?

In terms of a probabilistic inference, if we do not find evidence of sets of states that determine choice, then we should not believe that the probability of the effect (my choice) given some prior causal set (proximal mental states) is 1 . Instead, we should believe the probability is less than 1. But this is not unique to the case of choice; on probabilistic inferential models we almost never assign probabilities of 1 to causal outcomes. ${ }^{20}$ Thus, the format of the Probabilistic Account suggests that we should expect folk commitment to indeterminism in a great many areas that people do not obviously think are indeterministic. For example, some people may have beliefs of which they cannot find a deterministic cause among a sample of the mental states that enter into the formation of the belief. And yet there does not seem to be widespread acceptance of the view that belief formation, or even a substantial subset of belief formation, is indeterministic. $^{21}$

What is needed to avoid overgeneralization is some account of an asymmetry such that we probabilistically infer indeterminism in the case of choices but not in other cases. Strangely, despite the significant role overgeneralization plays in framing Nichols' critiques of opposing views, he makes no attempt to defend the Probabilistic Account from such worries. Acceptance

\footnotetext{
${ }^{20}$ Exceptions include logical or mathematical necessities, but these are not clearly causal cases.

${ }^{21}$ My experience with the religious beliefs of friends and colleagues are often of this form. They say things like, 'I can't say why, I just believe in God'.
} 
of (D2), supported by an IOED, was used to justify such an asymmetry in the Deductivist Account. Perhaps Nichols sees IOEDs playing a similar role for the Probabilistic Account?

We must proceed with caution when trying to apply the IOED literature to the Probabilistic Account. Certainly, if I believe that I have access to all the proximal causes of my choice then it is reasonable to believe that the proximal causes to which I have access are a representative sample. But one of the most appealing features of the Probabilistic Account is that it doesn't require the implausible belief that I have access to all the proximal causes of my own choice. If IOEDs are to be of any help, it would be by providing support for (P1), the assumption that introspection of the proximal influences on choice is a random and representative sample. Perhaps, as the result of an IOED, I believe that introspection of the proximal influences on my choice provides a random and representative sample. Thus, I believe something like (P1) in the case of choices but not in other cases.

I am suggesting here that the IOED literature could be used in the Probabilistic Account in much the same way it is pressed into service in the Deductivist Account. But the details are not entirely obvious. More to the point, if my objections to the use of IOEDs from section 2.3 work, then these problems will re-arise for the Probabilistic Account. So even if Nichols is implicitly assuming that the IOED literature prevents overgeneralization in the Probabilistic Account, the position remains untenable, given Spinozan strategy adequacy conditions. Are there other candidates to mark an asymmetry between inferences regarding indeterminism in the case of choices and other cases? Terry Horgan suggests that the very concept of free will biases our interpretation of experiences of choosing (Horgan 2012; 2011b). Thus, although he does not think that we experience our choices as indeterministic, he argues that we interpret our experiences as having indeterministic contents as the result of an 
interpretative bias. Since we do not bring the concept of free will to bear on our interpretations of other experiences, we do not infer indeterminism in cases other than choice.

Introducing an interpretative bias has the added benefit of addressing a lingering worry for the Spinozan strategy. Even if one successfully explains why people believe their choices to be indeterministic following the Spinozan strategy, it is not obvious why people seem to believe that they experience their choices as indeterministic. Why would so many people describe their experience of choice as indeterministic, if they don't have an experience of choice as indeterministic? Previously, the straight strategy had a leg up here. According to the straight strategy, people believe they experience their choices as indeterministic precisely because they do experience their choices as indeterministic. In short: the straight strategy can model belief about the experience of choice on belief about our experiences of almost everything else. By introducing an interpretative bias, the Spinozan strategy can explain why people believe they experience choice as indeterministic even though they don't have an experience of choice as indeterministic. They believe their experience of choice is indeterministic because there is a bias that affects their interpretation of their experiences.

While intriguing, the interpretative bias proposal is not of much help to the Probabilistic Account. It is the interpretive bias, and not probabilistic inference, that explains the belief in indeterministic choice. Thus, the Probabilistic Account becomes explanatorily inert. Furthermore, the interpretative bias proposal is cold comfort for the Spinozan strategist. Philosophers who use the Spinozan strategy are united in their rejection of the phenomenological claim that we experience choice as indeterministic. This rejection has seemed a powerful reason not to adopt the straight strategy. But this rejection seems unmotivated if, as the result of some bias, we always interpret our experience of choice as indeterministic. On what grounds could 
one possibly reject the phenomenological claim if we always interpret our experiences in line with that very claim?

\section{Conclusion}

As normally presented, the Spinozan strategy is incomplete. It holds that we infer that choice is indeterministic from the lack of an experience of choice as causally determined. But the lack of an experience of causal determination is extremely pervasive. Thus the Spinozan strategy is liable to overgeneralize without some account of an asymmetry between the case of choice and other cases. The Deductivist Account and the Probabilistic Account are explicitly crafted to address this overgeneralization worry. I have argued here that even these most sophisticated versions of the Spinozan strategy fail to avoid overgeneralization while remaining faithful to the fairly benign adequacy conditions of Scientific Plausibility and Reasonableness. In light of this failure, as well as the poor historical track record, there is mounting pressure against the Spinozan strategy. We should be pessimistic that other versions of the Spinozan strategy will fare much better.

Despite this mounting pressure, it is not yet time to give up on the Spinozan strategy. In the eyes of many philosophers, accepting that there is a widespread experience of choice as causally indeterministic is a bitter pill to swallow. To them, the alternative straight strategy gets the phenomenology wrong. By way of conclusion, then, it is valuable to map the remaining options available to these Spinozan strategists if they are to avoid overgeneralization.

The Spinozan strategy is a particular example of a broader form of inference. At the end of the day, the Spinozan strategy seeks to provide grounds that justify taking an absence of evidence (the lack of an experience of determinism) as evidence of absence (the absence of 
determined choice). Thus, in order to avoid overgeneralization, the Spinozan strategist must identify some asymmetry such that the inference seems prima facie plausible in the case of choices but not in the case of other phenomena. There are three options for locating such an asymmetry.

The asymmetry could be located in the inferential processes that give rise to the belief in indeterministic choice. That is, it could be the case that there exists a specialized inferential process that is specific to the case of choice. On this option, we believe choices are indeterministic, but not other phenomena like headaches, because the inferential process deployed in the case of choices is different from that in the case of headaches. This possibility was explored briefly in the discussion of an encapsulated IOED in the context of the Deductivist Account. As I argued in that discussion, there is currently no scientific motivation to think that any such specialized process uniquely obtains in the case of choice. Nevertheless, it is an empirical question worth pursuing.

A second option for the Spinozan strategist avoids overgeneralization by positing background assumptions that specifically constrain a more general inferential process in the case of choice. (D2) is an assumption of this kind; it operates on a general inferential process specifically in the case of choice, but not in other cases like headaches. While I have argued here that (D2) is not very plausible, there could be other assumptions that do similar work. For example, suppose there was a widely held background assumption of the following kind, 'For choice, unless determinism is explicitly detected, treat absence of evidence as evidence for absence'. If this kind of background assumption obtained, then a general inferential process could give rise to the belief in indeterministic choice without overgeneralizing. One of the lessons learned in the discussion of Nichols' accounts is that these assumptions must be fairly 
strong and domain specific if they are to meet Spinozan strategy adequacy conditions. As such, they tend to collapse into nativist assumptions, and are not currently supported by our best science. Nevertheless, whether a background assumption of this kind obtains is an empirical question worth pursuing further.

There is one more option available to the Spinozan strategist. The previous two options place constraints on the nature of the inferential process involved in order to block overgeneralization. Instead, the Spinozan strategist might change the inputs available to the inferential process in order to block overgeneralization. More specifically, if the experiences available in the case of choices are different from those available in other cases, then this could block the overgeneralization worry.

Fleshing out the story in serious detail would go far beyond the scope of this article, but it is worth making a few comments to indicate how the story might go. The Spinozan strategist claims that choices are not experienced as causally determined. This claim can be read in multiple ways. On one reading, they may be denying that choice is experienced as determined, while still allowing that choice is experienced as influenced by causal forces. Nichols and others adopt this interpretation. On the other reading, the Spinozan strategist might deny that choice is experienced as caused at all.

This latter reading opens up interesting possibilities for the Spinozan strategist. Certainly, we sometimes do seem to experience actions as caused, as when anger boils over, causing one to lash out in rage. However, in the deliberative context normally associated with making choices, it seems that we often lack an experience of choice as caused at all, deterministic or otherwise. That is, the contents of introspected mental states in the deliberative context are often not presented as causally efficacious. Rather, we tend to represent the contents 
of our mental states in the deliberative context as reasons that favor choosing a particular way. This marks an important difference between choices and other cases where the objects of experience may be presented as candidate recipients of causal force, and so could block overgeneralization. We might infer that the proximal influences on choices revealed via introspection are not causal determiners of choices because choices are not the right kinds of things to be caused at all, at least as presented in experience. More detail is obviously needed to show that this third option can successfully avoid overgeneralization while remaining faithful to Scientific Plausibility and Reasonableness, though I am optimistic that it is an avenue worth pursuing. Whichever of these three options Spinozan strategists pursue going forward, however, they would do well to keep overgeneralization worries in their sights at all times.

Andrew Kissel Department of Philosophy and Religious Studies Old Dominion University

\section{References}

Ahn, W., and Kalish, C. 2000: The role of mechanism beliefs in causal reasoning. In F. Keil and R. A. Wilson (Eds.), Explanation and Cognition (pp. 199-226). Boston, MA: MIT Press.

Butterfield, J. 2005: Determinism and indeterminism. In E. Craig (Ed.), Routledge Encyclopedia of Philosophy. London: Routledge.

Campbell, C. A. 1967: In Defence Of Free Will, With Other Philosophical Essays. London: Allen and Unwin.

Caruso, G. 2015: Free will eliminativism: reference, error, and phenomenology. Philosophical Studies, 172, 2823-2833. 
Deery, O. 2015: Is agentive experience compatible with determinism? Philosophical Explorations, 18(1), 2-19.

Deery, O., Bedke, M. S., and Nichols, S. 2013: Phenomenal abilities: incompatibilism and the experience of agency. In D. Shoemaker (Ed.), Oxford Studies in Agency and Responsibility (pp. 126-150). Oxford University Press.

Denison, S., Reed, C., and Xu, F. 2013: The emergence of probabilistic reasoning in very young infants: evidence from 4.5- and 6-month-olds. Developmental Psychology, 49(2), 243-249.

Dennett, D. 1984: Elbow Room. The MIT Press.

Fischer, J. M., and Ravizza, M. 1998: Responsibility and Control: A Theory of Moral Responsibility. Cambridge University Press.

Frankfurt, H. G. 1971: Freedom of the will and the concept of a person. Journal of Philosophy, 68(1), 5-20.

Gerken, L. 2010: Infants use rational decision criteria for choosing among models of their input. Cognition, 115(2), 362-366.

Holton, R. 2010: Disentangling the will. In R. Baumeister, A. R. Mele, and K. D. Vohs (Eds.), Free Will and Consciousness: How Might They Work? (pp. 82-100). Oxford: Oxford University Press.

2009: Willing, Wanting, Waiting. Oxford University Press.

Horgan, T. 2011a: Causal compatibilism about agentive phenomenology. In T. Horgan, M. Sabates, and D. Sosa (Eds.), Supervenience in Mind. Cambridge, MA: MIT Press. 2011b: The phenomenology of agency and freedom : lessons from introspection and lessons from its limits. Humana Mente, (15), 77-97. 
2012: Introspection about phenomenal consciousness: running the gamut from infallibility to impotence. In D. Smithies and D. Stoljar (Eds.), Introspection and Consciousness (pp. 405-421). Oxford University Press.

Kozuch, B., and Nichols, S. 2011: Awareness of unawareness. Journal of Consciousness Studies, $18(11-12), 135-160$.

Lawson, R. 2006: The science of cycology: failures to understand how everyday objects work. Memory and Cognition, 34(8), 1667-1675.

Levins, R. 1970: Complexity. In C. H. Waddington (Ed.), Towards a Theoretical Biology (pp. 67-86). Edinburgh: Edinburgh University Press.

Magill, K. 1997: Freedom and experience: self-determination without illusions. New York: St. Martin's Press.

Malle, B. F. 1999: How people explain behavior: a new theoretical framework. Personality and Social Psychology Review, 3(1), 23.

Malle, B. F., Knobe, J. M., and Nelson, S. E. 2007: Actor-observer asymmetries in explanations of behavior: new answers to an old question. Journal of Personality and Social Psychology, 93(4), 491-514.

Mawson, T. J. 2011: Free Will: A Guide for the Perplexed. Bloomsbury Academic.

Mills, C. M., and Keil, F. C. 2004: Knowing the limits of one's understanding: the development of an awareness of an illusion of explanatory depth. Journal of Experimental Child Psychology, 87, 1-32.

Nahmias, E., and Murray, D. 2010: Experimental philosophy on free will: an error theory for incompatibilist intuitions. In J. Aguilar, A. Buckareff, and K. Frankish (Eds.) (pp. 189215). Palgrave-Macmillan. 
Nichols, S. 2004: Folk concepts and intuitions: from philosophy to cognitive science. Trends in Cognitive Sciences.

2015: Bound: Essays on Free Will and Responsibility. Oxford University Press.

Nichols, S., and Knobe, J. 2007: Moral responsibility and determinism: the cognitive science of folk intuitions. Nô̂s, 41(4), 663-685.

Nisbett, R. E., and Wilson, T. D. 1977: Telling more than we can know: verbal reports on mental processes. Psychological Review, 84(3), 231-59.

O’Connor, T. 1995: Agent causation. In Agents, Causes, and Events: Essays on Indeterminism and Free Will (pp. 173-200). New York: Oxford University Press.

Pink, T. 2004: Free will a very short introduction. Oxford; New York: Oxford University Press.

Rakos, R. F., Steyer, K. R., Skala, S., and Slane, S. 2008: Belief in free will: measurement and conceptualization innovations. Behavior and Social Issues, 17(1), 20-39.

Romberg, A. R., and Saffran, J. R. 2010: Statistical learning and language acquisition. Wiley Interdisciplinary Reviews. Cognitive Science, 1(6), 906-914.

Rozenblit, L., and Keil, F. (n.d.). The misunderstood limits of folk science: an illusion of explanatory depth. Cognitive Science, 92(2002), 1-42.

Sarkissian, H., Chatterjee, A., De, F., Knobe, J., Nichols, S., and Sirker, S. 2010: Is belief in free will a cultural universal? Mind and Language, 25(3), 346-358.

Searle, J. R. 2003: Rationality in action. Cambridge, Mass.; London: MIT.

Sloman, S. A., and K., B. 2016: The basic assumptions of intuitive belief: laws, determinism, and free will. In L. Macchi, M. Bagassi, and R. Viale (Eds.), Cognitive Unconscious and Human Rationality (1st ed., pp. 167-180). MIT Press.

Smilansky, S. 2000: Free will and illusion. Oxford: Clarendon press. 
Sober, E. 2009: Absence of evidence and evidence of absence: evidential transitivity in connection with fossils, fishing, fine-tuning, and firing squads. Philosophical Studies, 143(1), 63-90.

Sommers, T. 2007: The illusion of freedom evolves. In D. Ross, D. Spurrett, H. Kincaid, and G. L. Stephens (Eds.), Distributed Cognition and the Will: Individual Volition in Social Context (pp. 61-75). MIT Press.

2015: Free will and experimental philosophy: an intervention. In Handbook of Neuroethics (pp. 273-286). Dordrecht: Springer Netherlands.

Soon, C. S., Brass, M., Heinze, H.-J., and Haynes, J.-D. 2008: Unconscious determinants of free decisions in the human brain. Nature Neuroscience, 11(5), 543-545.

Spinoza, B. de, and Hampshire, S. 2005: Ethics. (E. Curley, Trans.). Penguin Classics.

Swinburne, R. 2013: Mind, brain, and free will. Oxford: Oxford Univ. Press.

Tenenbaum, J. B., Griffiths, T. L., and Kemp, C. 2006: Theory-based bayesian models of inductive learning and reasoning. Trends in Cognitive Sciences, 10(7).

Vargas, M. 2013: Building Better Beings: A Theory of Moral Responsibility. Oxford Univ. Press. Wegner, D. M. 2003: The Illusion of Conscious Will. MIT Press.

Wimsatt, W. C. 2006: Aggregate, composed, and evolved systems: reductionistic heuristics as means to more holistic theories. Biology and Philosophy, 21(5), 667-702. 
